\begin{tabular}{c|c|c}
\hline $\begin{array}{c}\text { JURNAL PENELITIAN KEPERAWATAN } \\
\text { MEDIK }\end{array}$ & VOL. 1 NO. 2 & $\begin{array}{c}\text { EDITION: NOVEMBER 2018 }- \\
\text { APRIL 2019 }\end{array}$ \\
\hline & http://ejournal.delihusada.ac.id/index.php/JPKM & \\
\cline { 2 - 2 } & REVISED: 8 FEBRUARI 2019 & ACCEPTED: 10 MARET 2019 \\
\hline
\end{tabular}

\title{
GAMBARAN TINGKAT PENGETAHUAN PERSONAL HYGIENE TENTANG MENSTRUASI PADA SISWI SMP
}

\author{
Zaim Anshari \\ Universitas Islam Sumatera Utara, JI. STM No.77 Medan \\ Email: zaim.ashari@fk.uisu.ac.id
}

\begin{abstract}
During menstruation blood vessels in the uterus are very easily infected because germs easily enter and cause diseases of the reproductive tract. Some of the most common disorders are vaginal discharge and pruritus vulvae (vaginal itching). However, this complaint can be prevented by maintaining the cleanliness of the female organs early on, namely with good menstrual personal hygiene. This study aims to describe the level of personal hygiene knowledge about menstruation. This research is a descriptive study with a cross-sectional approach, with a total sample of 90 people taken by total sampling technique. The results showed that the majority of respondents had enough personal hygiene behavior as many as 82 people (91.1\%), while good menstrual personal hygiene behavior was 3 people (3.3\%), and respondents who had behaviors classified as less than 5 people ( $5.6 \%$ ). Based on complaints on reproductive organs, respondents who experienced vaginal discharge were 85 people $(94.4 \%)$ and itching around the genitals was around 83 people (92.2\%).
\end{abstract}

Kata Kunci : Perilaku, personal hygiene, menstruasi, remaja putri

\section{PENDAHULUAN}

Kesehatan reproduksi didefinisikan sebagai suatu kondisi sehat yang berkaitan dengan sistem, fungsi dan proses reproduksi yang ada pada manusia. Oleh karena itu pendidikan tentang kesehatan reproduksi terutama pada remaja dapat menjadi masalah penting yang perlu untuk diperhatikan oleh remaja, orang tua dan masyarakat. Pertumbuhan fisik dan seksual pada saat remaja mulai mengalami perkembangan pesat sehingga remaja perlu mengenal tubuh dan organ reproduksinya, baik itu perubahan fisik maupun psikologis yang terjadi pada dirinya agar dapat melindungi diri dari risiko yang mengancam kesehatan dan keselamatan fungsi organ reproduksi (Bobak, 2015).

Masa pubertas adalah masa peralihan menuju dewasa baik dari segi fisik maupun psikis. Tidak ada batasan yang pasti antara akhir masa kanak-kanak dan awal masa pubertas, akan tetapi dapat disimpulkan bahwa pubertas dimulai dengan awal berfungsinya ovarium pada remaja putri yaitu kira-kira sejak umur 8 hingga 14 tahun dan akan berlangsung tidak sampai 4 tahun. Kejadian yang penting untuk diperhatikan dalam masa remaja ialah terjadinya pertumbuhan tubuh yang cepat, munculnya ciri seks sekunder, terjadinya menstruasi dan perubahan psikis lainnya (Fitriyah, 2014). Remaja putri yang sudah matang alat reproduksinya maupun matang hormon-hormon dalam tubuhnya akan mengalami menstruasi atau proses perdarahan secara periodic yang disertai pelepasan endometrium yang mengandung pembuluh darah akibat sel telur yang tidak dibuahi.

Pengetahuan tentang proses menstruasi sangat penting diinformasikan kepada remaja putri sehingga mereka akan dapat menjaga kebersihan dirinya (personal hygiene). Kurangnya pengetahuan mengenai personal hygiene dapat meningkatkan resiko terjadinya 


\begin{tabular}{c|c|c}
\hline $\begin{array}{c}\text { JURNAL PENELITIAN KEPERAWATAN } \\
\text { MEDIK }\end{array}$ & VOL. 1 NO. 2 & $\begin{array}{c}\text { EDITION: NOVEMBER 2018 }- \\
\text { APRIL 2019 }\end{array}$ \\
\hline & http://ejournal.delihusada.ac.id/index.php/JPKM & \\
\cline { 2 - 2 } & REVISED: 8 FEBRUARI 2019 & ACCEPTED: 10 MARET 2019 \\
\hline
\end{tabular}

infeksi saluran kemih. Resiko lainnya seperti kejadian iritasi pada vagina juga sering terjadi akibat bahan kimia seperti sabun, spermisida, pembalut, dan lain lain, alergi dan dermatitis kontak serta adanya penyebab lain seperti polip servikalis atau neoplasma menjadi penyebab infeksi saluran kemih. Ketidakadekuatan hygiene merupakan salah satu faktor risiko terjadinya infeksi tersebut (Bobak, 2015).

Indikator Personal hygiene terdiri atas pengetahuan, sikap, dan tindakan proaktif diri untuk memelihara dan mencegah terjadinya risiko penyakit, maupun perlindungan diri dari ancaman penyakit (Laksamana, 2002). Salah satu upaya personal hygiene saat menstruasi adalah perilaku dan sikap berupa frekuensi mengganti pembalut setiap 4 jam sekali sehari maupun setelah mandi atau buang air, vagina sebaiknya dikeringkan terlebih dulu dengan tisu atau handuk agar tidak lembab. Pemakaian celana dalam yang terbuat dari bahan yang mudah menyerap keringat juga menjadi alternatif lainnya (Gustina, 2013).

Personal hygiene saat menstruasi pada remaja putri Sekolah Dasar Negeri Pisangan 1 misalnya menunjukkan bahwa mayoritas masih buruk, dimana $100 \%$ masih menggunakan sabun mandi untuk membersihkan vagina dengan alasan supaya bersih dan berasa nyaman (Fitriyah, 2014), 63\% suka memakai celana dalam yang ketat, $87 \%$ mengganti pembalut sebanyak 2-3 kali sehari dan tidak menggantinya setelah buang air besar maupun air kecil, serta $87 \%$ mengalami gatal-gatal saat menstruasi (Holloway, 2010). Sedangkan pada remaja putri di SMAN 1 Ngimbang menunjukkan peningkatan pengetahuan tentang personal hygiene dimana terdapat $59,5 \%$ mengganti pembalut setiap 4 jam sehari atau jika ada kontak pada udara, 34,2\% membasuh alat kelamin dari depan kebelakang dan $6,3 \%$ mengeringkan alat kelamin dengan celana dalam setelah dibasuh (Indah, 2012).

Hasil studi pendahuluan yang dilakukan di SMP Negeri 1 Kota Medan melalui wawancara lansung kepada 10 siswi kelas VII didapatkan bahwa $80 \%$ responden menyatakan mengganti pembalut sebanyak 2-3 kali sehari dan sisanya menyatakan tidak menggantinya setelah buang air besar maupun air kecil, 50\% menggunakan celana dalam yang ketat saat menstruasi, $70 \%$ masih menggunakan sabun mandi untuk membersihkan vagina, dan 50\% membasuh bagian luar organ genital setiap buang air kecil ataupun besar dari arah belakang ke depan.

Pembuluh darah dalam rahim sangat mudah terinfeksi ketika menstruasi karena kuman dapat mudah masuk akibat vagina yang lembab, pemakaian celana dalam yang tidak bersih yang pada akhirnya dapat menimbulkan penyakit pada saluran reproduksi. Panjang siklus haid bervariasi dipengaruhi oleh usia seseorang, panjang siklus haid pada wanita remaja rata-rata ialah 25,1 hari hingga 27,1 hari dan pada wanita dewasa adalah 51,9 hari. Jadi sebenarnya panjang siklus yang normal pada manusia ialah 25-32 hari, lamanya haid normal antara 3-5 hari, walaupun sebagaian wanita ada yang 1-2 hari masa haid diikuti sedikit darah. Pada setiap wanita normal lama haid itu tetap baik dari segi panjang siklus maupun lama haid (Fitriyah, 2014).

Siklus menstruasi dikontrol oleh hipotalamus dan kelenjar hipofisis anterior dengan jalur umpan balik antara otak dan ovarium yang melibatkan kadar estrogen sirkulasi. Saat gonadotrophin releasing hormone (GnRH) dilepas dari hipotalamus, hipofisis anterior terstimulasi untuk melepas follicle stimulating hormone (FSH), kemudian /uteinizing hormone (LH). FSH memulai aktivitasnya pada salah satu ovarium dan merangsang terjadinya pematangan beberapa folikel yang tersensitisasi. Estrogen yang dilepas dari folikel tersebut akan menyebabkan salah satu folikel dominan akan matang sementara folikel lain akan mengalami atresia dan pada saat kadar estrogen mencapai puncak, kelenjar hipofisis anterior melepas $\mathrm{LH}$, yang menyebabkan 


\begin{tabular}{c|c|c}
\hline $\begin{array}{c}\text { JURNAL PENELITIAN KEPERAWATAN } \\
\text { MEDIK }\end{array}$ & VOL. 1 NO. 2 & $\begin{array}{c}\text { EDITION: NOVEMBER 2018 - } \\
\text { APRIL 2019 }\end{array}$ \\
\hline & http://ejournal.delihusada.ac.id/index.php/JPKM & \\
\cline { 2 - 2 } & REVISED: 8 FEBRUARI 2019 & ACCEPTED: 10 MARET 2019 \\
\hline
\end{tabular}

folikel matur meluruh dan melepas ovum (Fitriyah, 2014).

Pertumbuhan organ reproduksi mengalami perubahan pada masa pubertas, terutama pada bagian payudara yang dimulai dari penonjolan puting disertai pembesaran daerah areola yaitu pada saat berusia sekitar 8-12 tahun. Menstruasi pertama atau menarche dapat terjadi pada stadium lanjut dari pubertas dan sifatnya sangat bervariasi untuk tiap individu. Setelah pertumbuhan payudara, pertumbuhan juga terjadi pada organ genital berupa pertumbuhan rambut pada pubis. Ratarata waktu yang dibutuhkan untuk mencapai pubertas yang lengkap adalah 2-5 tahun.

Perubahan pada organ reproduksi pada masa remaja berkaitan erat dengan perubahan regulasi hormonal yaitu regulasi pada sistem neuroendokrin yang dipengaruhi oleh pusat ekstra-hipotalamus di korteks serebri termasuk didalamnya adalah sistem limbik. Pusat ini akan merangsang sel basal hipotalamus untuk mensekresi hormon perangsang gonad. Hormon gonadotropin nantinya akan memproduksi hormon estrogen, pada saat dimulainya pubertas sekresi hormon $G n R H$ meningkat pesat sehingga hormon gonadotropin dan hormon seks steroid juga mengalami peningkatan yang bertujuan untuk merangsang pertumbuhan tanda seks sekunder, serta persiapan dalam menghadapi proses fertilisasi. Sejak pubertas, ovarium secara bergantian melepas satu ovum dari folikel de graaf (folikel yang telah matang)(Fitriyah, 2014).

Untuk itu dibutuhkan pengetahuan tentang personal hygiene yang merupakan suatu tindakan untuk memelihara kebersihan dan kesehatan seseorang untuk kesejahteraan fisik dan pskikis (Isro'in, 2014) sedangkan personal hygiene saat menstruasi dapat dilakukan berupa tindakan untuk memelihara kesehatan dan kebersihan pada daerah kewanitaan pada saat menstruasi Laksamana (2002).
Tujuan Perawatan Personal Hygiene, antara lain: untuk meningkatkan derajat kesehatan seseorang; memelihara kebersihan diri seseorang; memperbaiki personal hygiene yang kurang; pencegahan penyakit; meningkatkan percaya diri seseorang; dan menciptakan keindahan (Kusmiran, 2013).

Kesehatan organ reproduksi penting untuk dijaga agar fertilitas tetap terjaga sehingga mampu menghasilkan keturunan. Saat menstruasi tubuh cenderung memproduksi lebih banyak keringat, minyak dan cairan tubuh lainnnya. Sehingga seorang wanita harus tetap menjaga kebersihan dirinya terutama menjaga organ reproduksi wanita yaitu kesehatan vagina (Lianawati, 2013).

Menurut Holloway (2010), Organ reproduksi wanita sangat rentan terinfeksi bakteri yang akan menimbulkan bau yang tak sedap di daerah kelamin yang terinfeksi. Karena itu, wanita perlu menjaga kebersihan organ reproduksi dengan berbagai cara.

Cara pertama, pada saat mentruasi, wanita lebih berkeringat dibanding dengan hari biasa. Oleh karena itu, agar tubuh tetap segar dan bebas dari bau badan harus rajin merawat tubuh dengan mandi yang bersih dan mencuci rambut kemaluan minimal dua kali sehari. Saat menstruasi, wanita dianjurkan untuk mengganti pembalut secara teratur atau setelah buang air dan setelah mandi untuk menghindari pertumbuhan jamur dan bakteri pada daerah organ genital. Pembalut yang digunakan sebaiknya berbahan lembut, dapat menyerap air/keringat dengan baik, tidak mengandung bahan yang dapat menimbulkan alergi seperti bahan parfum dan gel yang dapat melekan dengan baik di pakaian dalam.

Cara kedua, yaitu mencuci bersih vagina setiap hari dengan cara membasuh dari arah depan vagina ke belakang anus secara hati-hati menggunakan air yang bersih setiap setelah buang air dan mandi.

Cara ketiga, biasakan mengeringkan alat kelamin dengan handuk atau kain lap yang 


\begin{tabular}{c|c|c}
\hline $\begin{array}{c}\text { JURNAL PENELITIAN KEPERAWATAN } \\
\text { MEDIK }\end{array}$ & VOL. 1 NO. 2 & $\begin{array}{c}\text { EDITION: NOVEMBER 2018 }- \\
\text { APRIL 2019 }\end{array}$ \\
\hline & http://ejournal.delihusada.ac.id/index.php/JPKM & \\
\cline { 2 - 2 } & REVISED: 8 FEBRUARI 2019 & ACCEPTED: 10 MARET 2019 \\
\hline
\end{tabular}

bersih sebelum menggunakan atau mengenakan pakaian dalam untuk menghindari lembab pada daerah vagina agar tidak menyebabkan pertumbuhan jamur. Selalu mengganti celana dalam minimal dua kali sehari. Celana dalam yang digunakan harus terbuat dari bahan yang mudah menyerap keringat. Hindari bertukar pakaian dalam dan handuk dengan orang lain karena hal ini dapat berpotensi menimbulkan penularan penyakit.

Hati-hati dengan penggunaan sabun antiseptik yang keras, cairan pewangi untuk menghilangkan bau di daerah vagina serta cairan kimia lainnya karena dapat membahayakan bagi kesehatan vagina. Membasuh vagina dengan bahan cairan kimia akan merusak keseimbangan yang ada sehimgga dapat terjadinya infeksi. Dianjurkan untuk mencukur rambut kemaluan agar tidak berpotensi untuk dihinggapi jamur atau kutu yang dapat menimbulkan rasa gatal dan infeksi (Manuaba, 2014; Notoatmodjo, 2014b).

Adapun faktor-faktor yang mempengaruhi personal hygiene adalah: praktik social, pilihan pribadi, citra tubuh, status sosial ekonomi (Isro'in, 2014). Manusia merupakan makhluk sosial dan karenanya berada dalam kelompok sosial. Kondisi ini akan memungkinkan seseorang berhubungan, berinteraksi dan bersosialisasi satu dengan yang lainnya.

Personal hygiene atau kebersihan diri seseorang sangat dipengaruhi oleh praktik sosial seseorang. Selama masa anak-anak, kebiasaan keluarga mempengaruhi praktik hygiene, misalnya frekuensi mandi dan waktu mandi. Pada masa remaja, hygiene pribadi dipengaruhi oleh kelompok teman sebaya. Remaja wanita misalnya akan mulai tertarik pada penampilan pribadi sehingga mereka mulai memakai riasan wajah. Pada masa dewasa seseorang akan menganggap teman dan kelompok kerja akan membentuk harapan tentang penampilan pribadi, sedangkan pada lansia hanya akan terjadi beberapa perubahan dalam praktik hygiene karena adanya perubahan dalam kondisi fisiknya.
Setiap orang berhak memiliki keinginan dan pilihan tersendiri dalam praktik personal hygiene termasuk memilih produk yang digunakan dalam praktik hygiene. Cara pandang seseorang terhadap bentuk tubuhnya disebut dengan citra tubuh. Citra tubuh sangat mempengaruhi dalam praktik hygiene seseorang, jenis dan tingkat praktik hygiene seseorang. Tingkatan sosial ekonomi yang rendah memungkinkan tingkat hygiene pseseorang menjadi rendah pula.

Hygiene merupakan standar tindakan seseorang untuk memelihara kebersihan dan kesehatan baik itu fisik dan psikis. Hygiene sangat penting dilakukan pada saat mengalami menstruasi, karena menstruasi akan menyebabkan tubuh mengeluarkan banyak keringat dan minyak yang berlebihan sehingga vagina akan rentan sekali terkena infeksi (Lianawati, 2014).

\section{METODE PENELITIAN}

Jenis penelitian ini adalah penelitian deskriptif dengan desain cross-sectional. Penelitian ini dilakukan di Kelas VII SMP Negeri 1 Kota Medan yang dimulai pada bulan Desember 2015. Populasi yang diambil dalam penelitian ini adalah Siswi SMP Negeri 1 yang sudah mengalami menstruasi yaitu 90 orang. Pengambilan sampel pada penelitian ini dengan menggunakan metode total sampling dimana seluruh populasi yang ada digunakan sebagai sampel (Notoatmodjo, 2014a).

Sampel adalah siswi kelas VII SMP Negeri 1 Medan yang telah mengalami menstruasi, dapat membaca, menulis, dan memahami informasi yang diberikan baik melalui verbal maupun tulisan, dan bersedia menjadi.

Alat ukur yang dipakai dalam penelitian ini adalah kuisioner yang terdiri dari 22 pertanyaan dengan hasil ukur baik jika nilai $76 \%-100 \%$, Sedang jika nilai $56 \%-75 \%$ dan Kurang jika nilai $<56 \%$.

Sebelum melakukan penelitian, peneliti meminta daftar nama siswi kelas VII ke bagian 


\begin{tabular}{c|c|c}
\hline $\begin{array}{c}\text { JURNAL PENELITIAN KEPERAWATAN } \\
\text { MEDIK }\end{array}$ & VOL. 1 NO. 2 & $\begin{array}{c}\text { EDITION: NOVEMBER 2018 - } \\
\text { APRIL 2019 }\end{array}$ \\
\hline & http://ejournal.delihusada.ac.id/index.php/JPKM & \multirow{2}{*}{ ACCEPTED: 10 MARET 2019 } \\
\cline { 2 - 3 } RECEIVED: 6 JANUARI 2019 & REVISED: 8 FEBRUARI 2019 &
\end{tabular}

tata usaha SMP Negeri 1 Medan setelah itu Peneliti meminta informed consent kepada semua sampel sebelum data diambil. Semua subjek penelitian dijelaskan maksud dan tujuan penelitian, selanjutnya apabila responden bersedia maka setiap responden menandatangani surat informed consent yang diberikan bersamaan dengan kuesioner. Setelah kuisioner diisi oleh responden selanjutnya peneliti melakukan editing, coding, tabulating, cleaning dan saving setelah itu dilakukan Analisa data menggunakan metode deskriptif yang hasilnya dipaparkan dalam bentuk tabel distribusi frekuensi.

\section{HASIL PENELITIAN}

Responden pada penelitian ini adalah remaja putrid kelas VII SMP Negeri 1 Medan yang sudah mengalami menstruasi. Sedangkan variabel yang diteliti adalah umur, usia

\begin{tabular}{lcc}
\hline Kategori & Frekuensi & $\begin{array}{c}\text { Persentase } \\
(\%)\end{array}$ \\
\hline Baik & 3 & 3,3 \\
Cukup & 82 & 91,1 \\
Kurang & 5 & 5,6 \\
\hline Jumlah & 90 & 100 \\
\hline menarche, perilaku personal hygiene, kejadian \\
keputihan, dan gatal-gatal pada organ \\
genitalia.
\end{tabular}

\section{a. Umur}

Frekuensi umur responden (tabel 1) terbanyak adalah umur 12 tahun sebanyak 56 orang $(62,2 \%)$, diikuti oleh umur 11 tahun sebanyak 25 orang $(27,8 \%)$, dan umur 13 tahun sebanyak 9 orang (10\%).

Tabel 1. Responden berdasarkan umur

\begin{tabular}{ccc}
\hline $\begin{array}{c}\text { Umur } \\
\text { (tahun) }\end{array}$ & $\begin{array}{c}\text { Jumlah } \\
(\mathbf{n})\end{array}$ & $\begin{array}{c}\text { Persentase } \\
(\%)\end{array}$ \\
\hline $\mathbf{1 1}$ & 25 & 27,8 \\
$\mathbf{1 2}$ & 56 & 62,2 \\
$\mathbf{1 3}$ & 9 & 10 \\
\hline Total & 90 & 100 \\
\hline
\end{tabular}

\section{b. Usia Menarche}

frekuensi usia termuda menstruasi (tabel 2) responden adalah 9 tahun dan tertua adalah 12 tahun. Usia saat pertama mesntruasi responden terbanyak adalah 12 tahun $(35,6 \%)$ dan paling sedikit adalah 9 tahun $(1,1 \%)$.

Tabel 2. Responden berdasarkan usia menarche

\begin{tabular}{ccc}
\hline $\begin{array}{c}\text { Usia } \\
\text { (tahun) }\end{array}$ & $\begin{array}{c}\text { Jumlah } \\
(\mathbf{n})\end{array}$ & $\begin{array}{c}\text { Persentase } \\
(\mathbf{\%})\end{array}$ \\
\hline $\mathbf{9}$ & 1 & 1,1 \\
$\mathbf{1 0}$ & 27 & 30 \\
$\mathbf{1 1}$ & 30 & 33,3 \\
$\mathbf{1 2}$ & 32 & 35,6 \\
\hline Total & 90 & 100 \\
\hline
\end{tabular}

\section{c. Personal Hygiene}

Responden yang memiliki perilaku personal hygiene yang baik sebanyak 3 orang (3,3\%), responden yang memiliki perilaku yang tergolong cukup sebanyak 82 orang $(91,1 \%)$, sedangkan responden yang memiliki perilaku yang tergolong kurang 5 orang $(5,6 \%)$ ditunjukkan oleh tabel 3 berikut.

Tabel 3. Responden Perilaku Personal Hygiene

\section{d. Kejadian Keputihan}

Seluruh remaja putri sebagai responden dalam penelitian ini sebanyak 85 orang mengalami keputihan $(94,4 \%)$ dan 5 orang tidak pernah mengalami keputihan $(5,6 \%)$. Jadi dapat disimpulkan bahwa mayoritas remaja putri ini pernah mengalami keputihan (lihat tabel 4).

Tabel 4. Kejadian Keputihan Pada Saat Menstruasi

\begin{tabular}{|c|c|c|}
\hline Kategori & Frekuensi & $\begin{array}{c}\text { Persentase } \\
(\%)\end{array}$ \\
\hline Ya & 85 & 94,4 \\
\hline Tidak & 5 & 5,6 \\
\hline Jumlah & 90 & 100 \\
\hline
\end{tabular}

Sebagian besar responden yang diteliti mengalami gatal-gatal di daerah kemaluan saat menstruasi yaitu 83 orang $(92,2 \%)$, 


\begin{tabular}{c|c|c}
\hline $\begin{array}{c}\text { JURNAL PENELITIAN KEPERAWATAN } \\
\text { MEDIK }\end{array}$ & VOL. 1 NO. 2 & $\begin{array}{c}\text { EDITION: NOVEMBER 2018 - } \\
\text { APRIL 2019 }\end{array}$ \\
\hline & http://ejournal.delihusada.ac.id/index.php/JPKM & \\
\cline { 2 - 2 } & REVISED: 8 FEBRUARI 2019 & ACCEPTED: 10 MARET 2019 \\
\hline
\end{tabular}

sedangkan yang tidak mengalami gatal-gatal adalah 7 orang $(7,8 \%)$.

Tabel 5. Kejadian Gatal-Gatal pada Organ Reproduksi Saat Menstruasi

\begin{tabular}{ccc}
\hline Kategori & Frekuensi & $\begin{array}{c}\text { Persentase } \\
(\%)\end{array}$ \\
\hline Ya & 83 & 92,2 \\
Tidak & 7 & 7,8 \\
\hline Jumlah & 90 & 100 \\
\hline
\end{tabular}

\section{PEMBAHASAN}

Rata-rata usia responden adalah 11,82 tahun dengan usia termuda adalah 11 tahun dan tertua adalah 13 tahun. Namun, sebagian besar responden ini adalah 12 tahun yaitu 56 orang $(62,2 \%)$ dan 11 tahun yaitu 25 orang $(27,8 \%)$. Berdasarkan tahap perkembangan, remaja dibagi menjadi tiga tahap yaitu remaja tahap awal yaitu mereka yang berusia 10-14 tahun, remaja tahap menengah yang berusia 15-16 tahun, dan remaja tahap akhir yaitu berusia 17-21 tahun (Bobak dkk, 2005). Dalam penelitian ini menunjukan bahwa rentang usia responden termasuk dalam masa remaja tahap awal yaitu antara usia 10-14 tahun (Prawirohardjo, 2015).

Sedangkan untuk usia pertama menstruasi, rata-rata pada usia 11,07 tahun, dengan usia termuda adalah 9 tahun dan tertua adalah 12 tahun. Usia remaja putri saat pertama menstruasi sebagaian besar adalah 12 tahun yaitu 34\% dan 11 tahun yaitu 30\%. Usia tersebut berada dalam rentang antara 10-19 tahun, dimana masa remaja ini merupakan periode terjadinya pematangan organ reproduksi manusia.

Secara garis besar, hasil penelitian yang telah dilakukan di Kelas VII SMP Negeri 1 Medan untuk melihat gambaran perilaku personal hygiene saat menstruasi pada remaja putri didapati perilaku personal hygiene yang baik sebanyak 3 orang $(3,3 \%)$, responden yang memiliki perilaku yang tergolong cukup sebanyak 82 orang $(91,1 \%)$, sedangkan responden yang memiliki perilaku yang tergolong kurang 5 orang (5,6\%).

Hasil penelitian berbeda dengan hasil penelitian Seperti pada penelitian Suryati (2012) pada remaja putri SMPN 2 Depok dari 186 responden didapatkan 143 orang $(76,9 \%)$ mempunyai perilaku kebersihan menstruasi yang baik, dimana perilaku tersebut ditunjang oleh frekuensi mengganti pembalut, menjaga kebersihan vagina, dan pemakaian celana dalam. ${ }^{13}$ Hasil penelitian ini juga berbeda dengan hasil penelitian yang dilakukan oleh Gustina (2013) pada remaja putrid SMP Muahamadiyah 9 yogyakarta didapatkan dari 79 responden, $87,5 \%$ berperilaku personal hygiene baik (Pudiastuti, 2013), sedangkan pada penelitian Rohmah (2013) yang dilakukan di kelas XI MAN Dolopo Kabupaten madiun dari 32 responden didapatkan $50 \%$ berperilaku personal hyigiene baik.

Perilaku-perilaku tersebut dipengaruhi oleh faktor internal dan eksternal. Adapun faktor internal yang mempengaruhi adalah umur dan intelegensi (tingkat kecerdasan). Adapun faktor eksternal yang mempengaruhi adalah informasi yang dapat menimbulkan kesadaran dan mempengaruhi perilaku (Suryati, 2013).

Faktor internal yang pertama adalah usia. Usia merupakan faktor yang menjadi penanda tingkat kematangan seseorang. Usia mempengaruhi daya tangkap informasi dan pola pikir seseorang, sehingga semakin dewasa umur seseorang, akan semakin banyak informasi yang di dapat dan semakin banyak pula hal yang dapat dikerjakan sehingga menambah pengetahuan untuk menjadikan individu lebih bijaksana, matang, dan lebih baik dalam berpikir maupun bertindak.

Selain umur, tingkat pengetahuan juga sangat berpengaruh terhadap perilaku. Pengetahuan adalah hasil penginderaan manusia terhadap objek melalui indera yang dimilikinya, baik pengelihatan, pendengaran, penciumana, rasa, dan raba. Pengetahuan ini merupakan konstruksi kognitif seseorang terhadapa objek, 


\begin{tabular}{c|c|c}
\hline $\begin{array}{c}\text { JURNAL PENELITIAN KEPERAWATAN } \\
\text { MEDIK }\end{array}$ & VOL. 1 NO. 2 & $\begin{array}{c}\text { EDITION: NOVEMBER 2018 }- \\
\text { APRIL 2019 }\end{array}$ \\
\hline & http://ejournal.delihusada.ac.id/index.php/JPKM & \\
\cline { 2 - 2 } & REVISED: 8 FEBRUARI 2019 & ACCEPTED: 10 MARET 2019 \\
\hline
\end{tabular}

pengalaman dan lingkungan yang telah diketahui, dipersepsikan, diyakini, sehingga menimbulkan motivasi niat untuk bertindak, sehingga menghasilkan sebuah perilaku.

Kurangnya informasi yang diterima maupun kesalahan informasi dapat menyebabkan individu berperilku kurang baik (Suryati, 2013). Hal ini sesuai dengan pernyataan Fitriyah (2014), yang menyatakan bahwa responden yang mendapatkan pendidikan kesehatan sebagian besar memiliki perilaku baik dan yang tidak mendapatkan pendidikan kesehatan sebagian besar memiliki perilaku yang kurang baik (Holloway, 2010).

Alat kelamin pada wanita yang sering berhubungan secara langsung dengan dunia luar yang jika berkelanjutan dapat menginfeksi selaput dinding perut (peritonitis). Namun, diketahui bahwa sistem pertahanan alat kelamin wanita cukup lemah sehingga infeksi sering susah dikendalikan dan menimbulkan keluhan klinis dari infeksi tersebut. Salah satu keluhannya yaitu keputihan (Tambak, 2014).

Keputihan ditandai oleh keluarnya cairan putih dari liang senggama secara berlebihan. Keputihan bukanlah suatu penyakit, tetapi gejala penyakit. Dalam jumlah lendir sedikit, keputihan tidak mengganggu aktivitas atau tidak menjadi keluhan wanita pada umumnya, namun demikian, keputihan jangan dianggap sebagai sesuatu yang biasa (Triana, 2013).

Dalam penelitian ini, sebagian besar responden yang mengalami keputihan ada 85 orang $(94,4 \%)$ sedangkan yang tidak pernah hanya 5 orang $(5,6 \%)$. Hal ini dipengaruhi oleh tindakan responden dalam menjaga kebersihan organ genitalia yang masih negatif, serta didukung oleh kebiasaan yang dianggap wajar padahal berisiko untuk terjadinya keputihan. Kebiasaan ini ditunjukan dengan kebiasaan membersihkan organ genitalia dari arah belakang ke depan, memakai celana dalam dari bahan nilon atau yang ketat dan tidak menyerap keringat, dan memakai antiseptik tanpa anjuran dari tenaga kesehatan. Hasil senada juga diungkapkan Sari (2010) yang menyatakan bahwa terdapat hubungan yang bermakna antara perilaku hygiene pribadi dengan kejadian keputihan dimana tingkat keputihan yang tinggi dapat berhubungan dengan perilaku hygiene pribadi yang kurang baik.

Keluhan yang dialami responden selain keputihan adalah rasa gatal pada daerah sekitar kemaluan pada saat menstruasi. Rasa gatal saat menstruasi atau yang disebut dengan pruritus vulvae. Pruritus vulvae merupakan akibat dari iritasi pada sekitar vulva dan lubang vagina yang biasa terjadi pada malam hari, iritasi ini bisa disebabkan oleh infeksi jamur, keputihan ataupun karena penggunaan sabun yang berlebihan pada vagina padahal tindakan ini tidak dianjurkan untuk kesehatan vagina (Tambak, 2014). Dalam penelitian ini dapat dilaporkan terdapat 83 orang responden $(92,2 \%)$ mengalami gatalgatal disekitar kemaluannya saat menstruasi dengan frekuensi kejadian pernah namun tidak setiap hari sebesar $16,7 \%$, sebagaimana hasil penelitian Triana (2010) yang menjelaskan bahwa $70 \%$ respondennya mengeluhkan keputihan yang berlebih dan gatal-gatal disekitar vagina, setelah diteliti lebih lanjut diperoleh bahwa ada kuman disekitar vagina, hal ini disebabkan oleh kurangnya menjaga kebersihan alat kelamin pada saat menstruasi dan pemakaian sabun pembersih vagina secara berlebihan (Wartonah, 2013).

\section{KESIMPULAN}

Berdasarkan hasil penelitian dan pembahasan mengenai pengetahuan tentang gambaran perilaku personal hygiene saat menstruasi pada Gambaran tingkat pengetahuan Personal Hygiene tentang Menstruasi Pada Siswi Kelas VII di SMP Negeri 1 Kota Medan Tahun 2016 dapat disimpulkan bahwa:

1. Remaja putri kelas VII SMP Negeri 1 Kota Medan rata-rata berusia 11,82 tahun dengan usia termuda 11 tahun dan tertua 10 tahun. Adapun rata-rata usia menarche adalah 11,07 tahun dengan usia termuda 9 tahun dan tertua 12 tahun.

2. Perilaku personal hygiene menstruasi yang baik ada sebanyak 3,3\%, responden yang 


\begin{tabular}{c|c|c|}
\hline $\begin{array}{c}\text { JURNAL PENELITIAN KEPERAWATAN } \\
\text { MEDIK }\end{array}$ & VOL. 1 NO. 2 & $\begin{array}{c}\text { EDITION: NOVEMBER 2018- } \\
\text { APRIL 2019 }\end{array}$ \\
\hline & http://ejournal.delihusada.ac.id/index.php/JPKM & \\
\cline { 2 - 3 } & REVISED: 8 FEBRUARI 2019 & ACCEPTED: 10 MARET 2019 \\
\hline
\end{tabular}

memiliki perilaku yang tergolong cukup sebanyak $91,1 \%$, sedangkan responden yang memiliki perilaku yang tergolong kurang 5,6\%.

3. Keluhan organ genitalia saaat menstruasi pada responden ada sebanyak 94,4\% keputihan dan $92,2 \%$ adalah gatal-gatal disekitar kemaluan. Berkaitan dengan frekuensi waktu gatal setiap hari selama menstruasi ada 83,3\% dan pernah namun tidak setiap hari sebesar $16,7 \%$.

\section{DAFTAR PUSTAKA}

Bobak, L. dan Jensen. 2015. Buku Ajar Keperawatan Maternitas. Jakarta: EGC.

Fitriyah, I. 2014. Gambaran Perilaku Higiene Menstruasi pada Remaja Putri di Sekolah Dasar Negeri di Wilayah Kerja Puskesmas Pisangan. Jakarta: Universitas Islam Negeri Syarif Hidayatullah.

Gustina, E. 2013. Sikap Dan Tindakan Tentang Mesntrual Hygiene Pada Remaja di SMP Muhamadiyah 9 Yogyakarta. Yogyakarta: Universitas Ahmad Dahlan.

Holloway. 2010. Nursing Consirderation in Patients with Vaginitis . US: Elsevier.

Indah, F. 2013. Kejadian Pruritus Vulvae Saat Menstruasi Pada Remaja Putri. Surabaya: Fakultas Kesehatan Masyarakat Universitas Airlangga.

Isro'in, L. dan Andarmoyo, S. 2014. Personal Hyigiene . Jakarta: Graha IImu.

Kusmiran, E. 2013. Kesehatan Reproduksi Remaja dan Wanita. Jakarta: Salemba Medika.

Laksamana. 2012. Kebutuhan Dasar Manusia. Jakarta: Gramedia Pustaka.

Lianawati, I. 2013. Tingkat Pengetahuan Remaja Putri Tentang Personal Higiene Saat Menstruasi pada Siswi Kelas X SMA
Islam Terpadu Al-Masyhur Pati Tahun 2013. Surakarta: Sekolah Tinggi IImu Kesehataan Kusuma Husada. 2014.

Manuaba, et al. 2014. Pengantar Kuliah Obstetri. Jakarta: Salemba Medika.

Notoatmodjo, S. 2014a. Metodologi Penelitian Kesehatan. Jakarta: Rineka Cipta.

Notoatmodjo, S. 2014b. Promosi Kesehatan dan Perilaku Kesehatan. Jakarta: Rineka Cipta.

Prawirohardjo, S. 2015. Ilmu Kandungan. Jakarta: YBPSP.

Pudiastuti, R. 2013. Tiga Fase Penting pada Wanita (Menarche, Menstruasi, Menopause). Jakarta: Salemba Medika.

Rohmah, E. 2013. Perilaku Remaja Putri Dalam Merawat Organ Genetalia Eksterna Selama Menstruasi Pada Siswi Kelas XI Di MAN Dolopo Kabupaten Madiun. Madiun: Harapan Mulya.

Suryati, B. 2013. Perilaku Kebersihan Remaja Saat Menstruasi. Jakarta: Poltekes Kemenkes.

Tambak, H. 2014. Hubungan Perilaku Menjaga Kebersihan Genitalia dengan Kejadian Keputihan Pada Siswi SMA Swasta Santo Thomas 2 Medan. Medan: Fakultas Kedokteran Universitas Sumatera Utara.

Triana, N. 2013. Faktor-Faktor yang Berhubungan dengan Perilaku Higiene Menstruasi di SMP Negeri 2 Bontang. Samarinda: Universitas Mulawarman.

Wartonah. dan Tarwoto. 2013. Kebutuhan Dasar Manusia dan Proses Keperawatan. Jakarta: Salemba Medika. 